\title{
Ferric Gluconate Complex in Elderly Hospital Inpatients without Terminal Kidney Failure
}

\author{
Patrick Viet-Quoc Nguyen and Judith Latour
}

\begin{abstract}
Background: Anemia is a common health issue for elderly patients. For patients with iron deficiency who cannot tolerate iron supplementation by the oral route, the parenteral route may be used. Options for parenteral iron supplementation include ferric gluconate complex (FGC).

Objectives: To evaluate the safety of FGC in elderly patients without terminal kidney failure and to assess its efficacy in treating iron-deficiency anemia.

Methods: An observational chart review was conducted at a tertiary care university health centre. Patients included in the study were 65 years of age or older, had received at least 1 dose of FGC between January 1, 2014, and December 31, 2015, and had a hemoglobin count of less than $130 \mathrm{~g} / \mathrm{L}$ (men) or less than $120 \mathrm{~g} / \mathrm{L}$ (women) at baseline. For each patient, the observation period began when the first dose of FGC was administered and ended 60 days after the last dose. The main safety outcome (occurrence of any adverse reaction) was evaluated for every patient, with the efficacy analysis being limited to patients with a diagnosis of irondeficiency anemia.

Results: A total of 144 patients were included in the study, of whom 76 had iron-deficiency anemia. No serious, life-threatening adverse reactions were reported. The most commonly reported adverse reactions were nausea and vomiting. The mean increase in hemoglobin count was $13.5 \mathrm{~g} / \mathrm{L}$, a statistically significant change from baseline.

Conclusions: These results show that FGC is safe for use in elderly patients, with very few mild adverse reactions. Use of FGC led to increased hemoglobin count within 60 days. Of the 3 options for parenteral iron supplementation available in Canada, iron sucrose has not been studied in elderly patients, and iron dextran has a higher incidence of anaphylaxis, whereas FGC appears to be a safe alternative for patients with intolerance to oral iron.
\end{abstract}

Keywords: elderly, iron, iron-deficiency anemia, hospital pharmacy service

\section{RÉSUMÉ}

Contexte : L'anémie est un problème de santé courant chez les patients âgés. Les patients qui présentent une carence en fer et une intolérance à la prise de suppléments de fer par la voie orale peuvent être traités par voie parentérale. Le complexe de gluconate ferrique de sodium (CGFS) représente l'une des options d'apport complémentaire en fer par voie parentérale.

Objectifs : Évaluer l'innocuité du CGFS chez le patient âgé qui n'est pas atteint d'insuffisance rénale terminale et évaluer son efficacité dans le traitement de l'anémie ferriprive.

Méthodes : Une analyse observationnelle a été menée au moyen des dossiers médicaux dans un établissement de santé universitaire de soins tertiaires. Les patients dont le dossier médical a été retenu pour l'analyse étaient âgés de 65 ans ou plus, avaient reçu au moins une dose de CGFS entre le 1er janvier 2014 et le 31 décembre 2015 et présentaient initialement un taux d'hémoglobine de moins de $130 \mathrm{~g} / \mathrm{L}$ (hommes) ou de moins de $120 \mathrm{~g} / \mathrm{L}$ (femmes). Pour chaque patient, la période d'observation s'étendait du moment où la première dose de CGFS avait été administrée au soixantième jour suivant la dernière dose. Le principal paramètre d'évaluation de l'innocuité (survenue de toute réaction indésirable) faisait l'objet d'une évaluation pour chaque patient. L'analyse de l'efficacité se limitait aux patients ayant reçu un diagnostic d'anémie ferriprive.

Résultats : Au total, 144 patients ont été admis à l'étude et, parmi eux, 76 présentaient une anémie ferriprive. Aucune réaction indésirable grave menaçant la vie du patient n'a été notée. Les réactions indésirables les plus souvent signalées étaient des nausées et des vomissements. L'augmentation moyenne des taux d'hémoglobine était de $13,5 \mathrm{~g} / \mathrm{L}$, un changement statistiquement significatif comparé à la valeur de départ.

Conclusions : Les résultats montrent que le CGFS est sécuritaire pour le patient âgé et qu'il ne provoque que très peu de réactions indésirables légères. L'emploi du CGFS a produit une augmentation des taux d'hémoglobine en moins de 60 jours. Parmi les 3 options d'apport complémentaire en fer pris par voie parentérale disponibles au Canada, le fer-saccharose n’a pas été étudié auprès de patients âgés et le fer-dextran est associé à une plus grande incidence de cas d'anaphylaxie; or, le CGFS semble être une solution sécuritaire pour les patients qui présentent une intolérance au fer administré par voie orale.

Mots clés : patients âgés, fer, anémie ferriprive, service de pharmacie en établissement de santé 


\section{INTRODUCTION}

7 he World Health Organization (WHO) has defined anemia as a condition in which hemoglobin count is less than $120 \mathrm{~g} / \mathrm{L}$ in women and less than $130 \mathrm{~g} / \mathrm{L}$ in men. ${ }^{1}$ There is some debate about the definition of anemia in older adults; however, the WHO definition is the one most frequently used in epidemiologic studies. Anemia is a common health issue for elderly patients. Its prevalence increases with age, and it affects $7.8 \%$ of men and $8.5 \%$ of women aged 65 to 74 years, $15.7 \%$ of men and $10.3 \%$ of women aged 75 to 84 years, and $26.1 \%$ of men and $20.1 \%$ of women aged 85 years or older. ${ }^{2}$ Anemia is associated with cognitive decline and increased risk of death in the elderly population. ${ }^{3,4}$

Anemia occurs in the presence of a depressed level of hemoglobin. ${ }^{5-7}$ Among cases where a cause for the anemia can be identified, the most common causes are deficiency of iron, folate, or vitamin $\mathrm{B}_{12}$; kidney failure; and chronic inflammation. However, a large proportion of cases remain unexplained. The treatment focuses on increasing iron stores through supplementation. Iron by oral administration is usually the first-line treatment, because of its low cost and less invasive mode of administration. However, its use is often limited by adverse reactions such as nausea, vomiting, constipation, abdominal pain, diarrhea, black stool, and metallic taste..$^{8-10}$ Elderly patients are vulnerable to these reactions, especially when high doses are administered. ${ }^{5,11}$ Furthermore, iron absorption can be hindered by reduced production of stomach acid and the widespread use of proton pump inhibitors. ${ }^{12,13}$

Parenteral iron supplementation is an alternative mode of administration that leads to more effective and more rapid increases in hemoglobin than occur with oral iron. ${ }^{5}$ Parenteral administration can improve iron stores without concern about absorption or gastrointestinal side effects. ${ }^{6,14}$ It is usually recommended in situations of intolerance, contraindications, or inadequate response to oral iron. ${ }^{7,15}$ The use of these forms of iron was previously limited by the associated risk of hypersensitivity reaction, especially with the iron dextran compound. Dextran, sucrose, and ferric gluconate complex (FGC) are the only parenteral iron salts currently available in Canada. For this study, FGC was used because of its lower risk of hypersensitivity reaction and lower cost, relative to the dextran and sucrose forms. ${ }^{6,14}$

In fact, FGC is indicated for treating iron-deficiency anemia in patients undergoing long-term hemodialysis who are receiving supplemental erythropoietin therapy, and the drug has to date been studied only in this context. ${ }^{16}$ In clinical practice, FGC is also administered to elderly patients with other conditions.

The main goal of this study was to evaluate the safety of FGC in patients aged 65 years or older without terminal kidney failure. The secondary objective was to evaluate the effect of FGC on hemoglobin count. Ferritin and transferrin saturation are better than hemoglobin as markers of iron therapy response. However, these markers were deemed unsuitable for the current retrospective study, because they are not systematically measured in patients receiving parenteral iron; as such, many data would be missing, which would render any comparisons irrelevant.

\section{METHODS}

This observational chart review was carried out at the Centre hospitalier de l'Université de Montréal (CHUM), a tertiary care university health centre. To identify eligible participants, a computer-generated list of all patients 65 years of age or older who had received at least 1 dose of FGC from January 1, 2014, to December 31, 2015, was reviewed. For each patient, the observation period began when the first dose of FGC was given and ended 60 days after the last dose. FGC was administered as $125 \mathrm{mg}$ diluted in $100 \mathrm{~mL}$ of $0.9 \%$ sodium chloride (normal saline solution) and infused intravenously over $60 \mathrm{~min}$.

The following inclusion and exclusion criteria were applied. Men were included if their hemoglobin count was less than $130 \mathrm{~g} / \mathrm{L}$ before receiving FGC, and women if their hemoglobin count was less than $120 \mathrm{~g} / \mathrm{L}$. Only patients with a hemoglobin count during the 60 days after the last FGC dose were included. Patients were excluded if they received an FGC dose in the ambulatory care unit without being admitted to the hospital as an inpatient. Patients with active bleeding and those receiving palliative care were also excluded. This study focused on patients without terminal kidney failure, a population that has not been considered in previous studies. Therefore, patients receiving hemodialysis and those with terminal renal failure (creatinine clearance $<10 \mathrm{~mL} / \mathrm{min}$ ) were excluded. Patients were also excluded if they were given any other type of parenteral iron, erythropoietin, or more than 7 days of oral iron in the 2 months before or during the study. Patients who received a blood transfusion during the study period and those whose FGC perfusion occurred over a period of more than 30 days were also excluded. For patients with multiple admissions during the study period, data were analyzed for only the first admission.

Because the study goal was to assess the safety of FGC, a diagnosis of iron-deficiency anemia was not required. FGC is prescribed for every patient receiving total parenteral nutrition (TPN) in the study hospital, with FGC and TPN being administered separately to all patients without contraindications. The FGC dose varied according to the patient's hemoglobin value. Patients receiving FGC with TPN were included in the study, as were patients with mixed-type anemia who received FGC. However, for the efficacy analysis, only patients with irondeficiency anemia, as diagnosed by the responsible physician, were included.

The study was approved by the CHUM Research Centre Ethics Committee. Given the observational nature of the study, participants' consent was not required; in addition, identifying information was removed from the data at the beginning of the analysis. 
This single copy is for your personal, non-commercial use only.

For permission to reprint multiple copies or to order presentation-ready copies for distribution, contact CJHP at publications@cshp.ca

\section{Outcome Measures}

Demographic and medical data were extracted from the medical records. Information about the cause and type of anemia was collected. The following common causes of iron-deficiency anemia $^{7,9}$ were also collected, if this information had been entered in the chart by the responsible physician: malnutrition, gastrectomy, duodenal bypass, Helicobacter pylori infection, tumours, intestinal cancer, inflammatory bowel disease, angiodysplasia, hemorrhoids, diverticulitis, intravascular hemolysis, menorrhagia, systemic bleeding, malabsorption syndrome, and thalassemia. The use of certain medications, such as nonsteroidal anti-inflammatory drugs, anticoagulants, and proton pump inhibitors, was also collected. The iron deficit for each patient (i.e., the total iron dose required) was calculated using the following formula: body weight $\times$ (desired hemoglobin - observed hemoglobin) $\times 2.4+500 \mathrm{mg}^{17}$

The main safety outcome (occurrence of adverse reactions) was systematically evaluated for each patient. Vital signs were assessed by nursing staff 3 times per day and during the hour following FGC infusion, and any adverse reactions were to be documented at the same time. The medical and nursing observation sheets were actively searched for known adverse reactions (i.e., anaphylaxis, nausea, vomiting, pruritus, flushing, myalgia, arthralgia, back pain, chest pain, hypotension, drowsiness, and dizziness) that occurred during FGC administration or in the subsequent $24 \mathrm{~h}$. All adverse reactions described by a physician, nurse, or pharmacist were recorded for analysis. Reactions were defined as severe if they were life-threatening, caused permanent damage, or required intensive care; moderate if a specific therapy was needed to prevent further reaction; and mild if they required no therapy and resolved within $24 \mathrm{~h}$. The Naranjo algorithm ${ }^{18}$ was used to determine the likelihood of an adverse drug reaction being due to the drug, with a score of $1-4$ indicating a possible adverse drug reaction, a score of 5-8 indicating a probable adverse drug reaction, and a score of 9 or higher indicating a certain adverse drug reaction.

The primary efficacy outcome was determined as an increase in hemoglobin count during the 60 -day observation period. The following elements of complete blood count were also evaluated in the efficacy analysis: hematocrit, mean corpuscular volume (MCV), and mean corpuscular hemoglobin concentration (MCHC). Values for ferritin, serum iron, transferrin, and total iron-binding capacity were also collected. For the purposes of this analysis, data were collected for baseline and for 3 periods after each patient's last FGC dose (1-14 days, 15-30 days, and 31-60 days). If a patient had more than one result available for a particular period, the mean value was calculated. All measurements were performed with the Sysmex XE-2100 blood analyzer, and quality control was performed daily. The acceptable standard deviation of this system was $1 \%$.

\section{Statistical Analysis}

Continuous variables with normal distribution are reported as means with standard deviation (SD), and categorical variables are reported as proportions. The safety outcome was also described using proportions. The efficacy of FGC was evaluated in terms of the difference between the baseline and highest values for hemoglobin, hematocrit, MCV, and MCHC during the study period. The same analysis was performed for the cumulative 14-, 30-, and 60-day periods. These comparisons were tested statistically with the $t$ test for paired observations. Subgroup analyses were performed for 3 variables: FGC dose (comparing total doses of 125-374 mg, 375-624 mg, and 625-1000 mg), frequency of administration (daily versus interval of $48 \mathrm{~h}$ or longer), and kidney function (based on a categorical variable for creatinine clearance: $\leq 60 \mathrm{~mL} / \mathrm{min}$ or $>60 \mathrm{~mL} / \mathrm{min}$ ). For all subgroup analyses, differences in continuous variables were evaluated using analysis of variance with Bonferroni correction. The dichotomous analysis for hemoglobin increase was performed with the $\chi^{2}$ test for the subgroup analyses based on kidney function and daily versus less frequent administration and by logistic regression for the subgroup analysis based on FGC dose. Missing data are inherent to retrospective, chart-based studies. By default, all missing data for categorical variables were assigned a value of 0 (meaning "not present"), and all missing data for continuous variables were deemed to be "missing", with no value assigned.

SPSS software (IBM, Armonk, New York) was used for the statistical analyses, and an $\alpha$ value of less than 0.05 was chosen to indicate statistical significance.

\section{RESULTS}

From January 1, 2014, to December 31, 2015, the pharmacy registry files showed an entry for dispensing of FGC for 684 patients. Of these, 144 met the eligibility criteria and were included in the current study (Figure 1). Baseline characteristics are reported in Table 1 . The mean age was 77 years, and 71 (49\%) of the patients were men.

Seventy-six patients had a diagnosis of iron-deficiency anemia. Twenty-nine of these patients had mixed-type anemia: 20 with kidney failure anemia, 6 with chronic inflammation anemia, and 3 with vitamin $B_{12}$ deficiency. Thirty-six of the patients with iron-deficiency anemia had no documented risk factor. The 68 patients without a diagnosis of anemia were receiving TPN; these patients were excluded from the efficacy analysis. Table 2 describes the FGC dosage for all 144 patients.

\section{Clinical Outcomes}

A total of 402 doses of FGC were administered to the 144 patients. No serious, life-threatening adverse reactions were reported in any patient chart. Less serious adverse reactions were reported for 16 patients (11\%): 9 patients with a single adverse 
reaction and 7 patients with 2 adverse reactions. The most frequent side effects were nausea and vomiting, both of which affected 8 patients (6\%); in addition, 3 patients (2\%) experienced hypotension. Chest pain, dizziness, headache, and lower leg pain were each reported for 1 patient. All adverse reactions were scored as "possibly" related to FGC, according to the Naranjo algorithm.

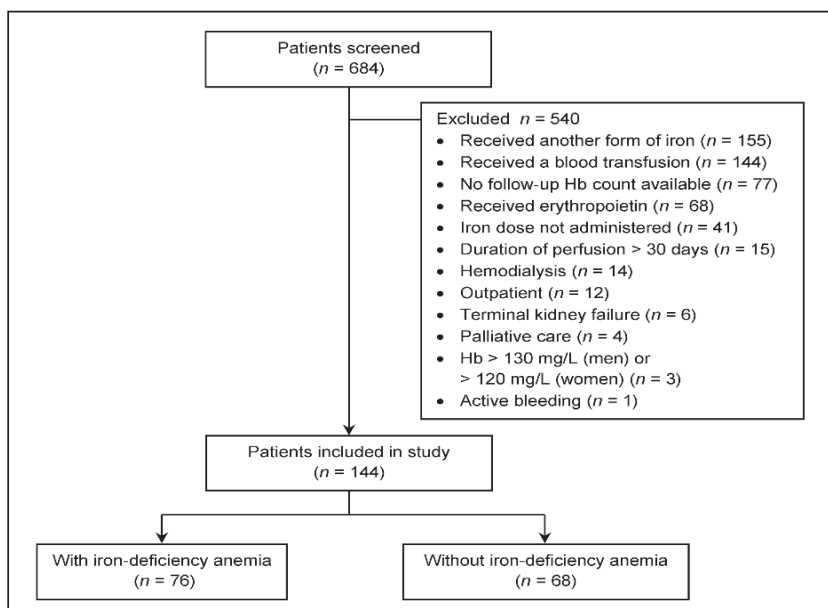

Figure 1. Study flow chart. $\mathrm{Hb}=$ hemoglobin.
Among the 76 patients with iron-deficiency anemia, complete blood count data were available for 60,42 , and 35 patients for days 1-14, 15-30, and 31-60, respectively (Table 3). Baseline values for ferritin, serum iron, transferrin, and total ironbinding capacity were available for 23 patients. The mean total dose of FGC administered to patients with iron-deficiency anemia was $458 \mathrm{mg}$ (SD $304 \mathrm{mg}$ ). The calculated iron deficit was available for 70 patients (mean deficit $1161 \mathrm{mg}$, SD $301 \mathrm{mg}$ ), 6 of whom received an appropriate FGC dose. The highest mean hemoglobin value obtained during the observation period was $105 \mathrm{mg}$ (SD $14 \mathrm{~g} / \mathrm{L}$ ). During their respective observation periods, $14(18 \%)$ of the 76 patients achieved an increase of up to $10 \mathrm{~g} / \mathrm{L}$, $11(14 \%)$ had an increase between 10.1 and $15 \mathrm{~g} / \mathrm{L}$, and $18(24 \%)$ had an increase of 15.1 to $20 \mathrm{~g} / \mathrm{L}$. The mean increase in hemoglobin count was $13.5 \mathrm{~g} / \mathrm{L}$ (95\% CI 10.3-16.7 g/L). The difference in hemoglobin count relative to baseline was statistically significant for each of the subdivided observation periods and the overall period $(p<0.01)$. Similarly, hematocrit levels were significantly superior to baseline during the subsequent observation periods $(p<0.01)$. Mean hematocrit increased by $3.2 \%$, $4.7 \%$, and $4.2 \%$ during days $1-14$, days $15-30$, and days $31-60$, respectively, and by $4.7 \%$ across the overall observation period.

Table 1. Demographic and Clinical Characteristics of the Study Population

\begin{tabular}{|c|c|}
\hline Characteristic & $\begin{array}{c}\text { No. (\%) of Patients* } \\
(n=144)\end{array}$ \\
\hline$\overline{\text { Age (years) (mean } \pm \text { SD) }}$ & $77 \pm 7.8$ \\
\hline Sex, male & $71(49)$ \\
\hline Weight (kg) (mean \pm SD) & $68 \pm 19$ \\
\hline Baseline hemoglobin (g/L) (mean \pm SD) & $92.9 \pm 12.5$ \\
\hline \multicolumn{2}{|l|}{ Kidney function } \\
\hline $\mathrm{CrCL}(\mathrm{mL} / \mathrm{min})(\operatorname{mean} \pm \mathrm{SD})$ & $58 \pm 27$ \\
\hline Mild-moderate kidney disease ( $\mathrm{CrCL} 30-60 \mathrm{~mL} / \mathrm{min})$ & $49(34)$ \\
\hline Severe kidney disease (CrCL 10-30 mL/min) & $26(18)$ \\
\hline \multicolumn{2}{|l|}{ Risk factors for iron-deficiency anemia } \\
\hline Systemic bleeding & $24(32)$ \\
\hline Malnutrition & $6 \quad(8)$ \\
\hline Intestinal cancer & $5(7)$ \\
\hline Angiodysplasia & $5(7)$ \\
\hline Diverticulitis & $3(4)$ \\
\hline Hemorrhoids & $2(3)$ \\
\hline Inflammatory bowel disease & $2(3)$ \\
\hline Gastrectomy & $2(3)$ \\
\hline B-Thalassemia & $1(1)$ \\
\hline Hypersplenism & $1(1)$ \\
\hline \multicolumn{2}{|l|}{ Concomitant medication } \\
\hline Proton pump inhibitor & $109(76)$ \\
\hline Anticoagulant & $28(19)$ \\
\hline NSAID & $19(13)$ \\
\hline
\end{tabular}

$\mathrm{CrCL}=$ creatinine clearance (calculated with Cockcroft-Gault equation),

NSAID = nonsteroidal anti-inflammatory drug, SD = standard deviation.

*Except where indicated otherwise.

tCalculated for the 76 patients with iron deficiency anemia. 


\section{Subgroup Analyses}

In patients with iron-deficiency anemia, total FGC doses of $125-374 \mathrm{mg}$ ( $n=29$ patients), 375-624 mg ( $n=25)$, and $625-1000 \mathrm{mg}(n=22)$ led to increases in hemoglobin count of $10.5,16.1$, and $14.4 \mathrm{~g} / \mathrm{L}$, respectively (Table 4). The increase was similar across the 3 groups. Creatinine clearance was available for 70 patients, 26 with a value of $60 \mathrm{~mL} / \mathrm{min}$ or less and 44 with a value higher than $60 \mathrm{~mL} / \mathrm{min}$. There was no statistically significant difference in hemoglobin increase between these 2 groups. Among the 76 patients who received more than 1 FGC dose, 51 received FGC every $24 \mathrm{~h}$ (mean total FGC administered $571 \mathrm{mg}$ [SD $291 \mathrm{mg}]$ ), and 25 received FGC at intervals of $48 \mathrm{~h}$

\section{Table 2. FGC Dosage and Number of Doses Administered}

\begin{tabular}{lcc} 
FGC Dosage & $\begin{array}{c}\text { No. (\%) of } \\
\text { Patients } \\
(\boldsymbol{n}=\mathbf{1 4 4 )}\end{array}$ & $\begin{array}{c}\text { Mean No. of } \\
\text { Doses } \\
\text { Administered }\end{array}$ \\
\hline 125 mg once daily & $53(37)$ & 3.4 \\
125 mg once every 2 days & $23(16)$ & 4.0 \\
125 mg once every 3 days & $4(3)$ & 3.3 \\
125 mg once a week & $42(29)$ & 1.8 \\
125 mg once every 2 weeks & $22(15)$ & 1.3 \\
\hline
\end{tabular}

$\mathrm{FGC}=$ ferric gluconate complex. or longer (mean total FGC administered $505 \mathrm{mg}$ [SD $273 \mathrm{mg}]$ ). There was no significant difference in hemoglobin increase between these 2 groups.

\section{DISCUSSION}

In clinical practice, FGC is often administered to treat iron-deficiency anemia, mainly because of the shorter duration of therapy relative to that of oral iron, as well as more rapid onset and lower rate of gastrointestinal adverse reactions, especially constipation. ${ }^{7,15}$ It is also a good alternative when the oral route is unavailable. However, evidence for use of FGC in patients who are not receiving hemodialysis is scarce.

An open-label randomized trial involving 113 patients compared oral iron $(n=25)$ with FGC $500 \mathrm{mg}(n=41)$ and FGC $1000 \mathrm{mg}$ (given in 8 doses of $125 \mathrm{mg}$ each; $n=47$ ) during hemodialysis sessions. ${ }^{16}$ The mean age was $55,57.1$, and 52.2 years for the 3 groups, respectively. The increase in hemoglobin with the higher dose of FGC was statistically greater than that achieved with oral iron, but there was no difference between oral iron and the lower dose of FGC. No severe adverse reactions (including anaphylaxis) were reported, but there were some mild adverse reactions, such as nausea, vomiting, and rash. Another study compared the efficacy and safety of FGC and iron sucrose

Table 3. Hematologic Results for Patients with Iron-Deficiency Anemia

\begin{tabular}{|c|c|c|c|c|}
\hline \multirow[b]{2}{*}{ Variable } & \multicolumn{4}{|c|}{ Timeframe; Mean \pm SD } \\
\hline & $\begin{array}{l}\text { Baseline } \\
(n=76)\end{array}$ & $\begin{array}{c}\text { Day 1-14 } \\
(n=60)\end{array}$ & $\begin{array}{c}\text { Day 15-30 } \\
(n=42)\end{array}$ & $\begin{array}{c}\text { Day 31-60 } \\
(n=35)\end{array}$ \\
\hline Hemoglobin (g/L) & $91 \pm 12$ & $96 \pm 12$ & $103 \pm 16$ & $104 \pm 15$ \\
\hline Hematocrit & $0.28 \pm 0.05$ & $0.32 \pm 0.04$ & $0.33 \pm 0.05$ & $0.32 \pm 0.07$ \\
\hline$M C V(f L)$ & $86 \pm 7$ & $89 \pm 6$ & $88 \pm 6$ & $88 \pm 6$ \\
\hline $\mathrm{MCHC}(p g)$ & $27 \pm 3$ & $28 \pm 2$ & $28 \pm 3$ & $28 \pm 2$ \\
\hline Ferritin $(\mu \mathrm{g} / \mathrm{L})^{*}$ & $57.5 \pm 48$ & - & - & - \\
\hline Transferrin saturation* & $0.09 \pm 0.04$ & - & - & - \\
\hline
\end{tabular}

\section{Table 4. Change in Hemoglobin in Patients with Iron-Deficiency Anemia (Subgroup Analyses)}

\begin{tabular}{|c|c|}
\hline Subgroup & $\begin{array}{l}\text { Change in Hemoglobin (g/L)* } \\
\text { (Mean and } 95 \% \mathrm{Cl} \text { ) }\end{array}$ \\
\hline \multicolumn{2}{|l|}{ Total FGC dose administered } \\
\hline $125-374 \mathrm{mg}(n=29)$ & $10.5(6.1$ to 15.0$)$ \\
\hline $375-624 \mathrm{mg}(n=25)$ & 16.1 (9.4 to 22.8$)$ \\
\hline $625-1000 \mathrm{mg}(n=22)$ & 14.4 (8.4 to 20.4$)$ \\
\hline \multicolumn{2}{|l|}{ Kidney function } \\
\hline $\mathrm{CrCl} \leq 60 \mathrm{~mL} / \min (n=26)$ & 14.0 (9.8 to 18.3$)$ \\
\hline $\mathrm{CrCl}>60 \mathrm{~mL} / \min (n=44)$ & $14.1(9.3$ to 18.9$)$ \\
\hline \multicolumn{2}{|l|}{ Frequency of FGC administration } \\
\hline 125 mg every $24 \mathrm{~h}(n=51)$ & $14.7(-0.5$ to 29.9$)$ \\
\hline 125 mg every $48 \mathrm{~h}$ or longer $(n=25)$ & $11.0(0.6$ to 21.4$)$ \\
\hline
\end{tabular}


in 55 patients receiving hemodialysis (mean age 59 years). ${ }^{19}$ There was no statistically significant difference between the 2 groups in terms of efficacy and safety. Various trials have assessed the safety of FGC in patients receiving hemodialysis without a test dose, in iron dextran-sensitive and iron dextran-tolerant patients, and in patients receiving a dose of $250 \mathrm{mg}$ or more. ${ }^{20-23}$ All of the patients in these studies were receiving hemodialysis, and the mean age ranged from 50 to 60 years. There was only one case of anaphylaxis with exposure of more than 5000 patients, and the other side effects were mild to moderate. ${ }^{20-23}$ No studies investigating FGC in non-hemodialysis patients or in an elderly population were found in the literature. The current study therefore provides a first insight into the safety and efficacy of FGC in elderly patients who are not receiving hemodialysis.

This study has shown that FGC is safe for elderly patients without kidney failure and those with mild to severe kidney failure, as no severe adverse reactions and only a few mild adverse reactions were reported. These results indicate that the FGC safety profile, based on results of prior clinical trials involving younger patients receiving hemodialysis, ${ }^{20-22}$ can be extended to elderly patients. This is not surprising, given that hemodialysis patients have many comorbidities and may be sicker than hospitalized elderly patients. Some aspects of this therapy remain to be explored; for example, adverse reactions were not assessed prospectively, and the study population was rather small for detecting serious adverse effects. For confirmation of these findings, a larger sample would be necessary, given the low incidence of serious adverse reactions, especially with low doses. ${ }^{24}$ In addition, the possibility of anaphylaxis cannot be excluded. As reported in here, hypotension may occur after the infusion; therefore, caution and monitoring are required.

FGC use was associated with increases in hemoglobin count and hematocrit in elderly patients with anemia. Despite these increases, it is likely that patients' iron storage was not fully restored, given that the dose administered was less than the calculated iron deficit. Nonetheless, augmentation was superior to that reported in previous trials, despite the lower total infused dose. In the study by Nissenson and others, ${ }^{16}$ a 500 -mg dose of FGC led to an increase in hematocrit of $5 \mathrm{~g} / \mathrm{L}$, whereas a $1000-\mathrm{mg}$ dose led to an increase of $13 \mathrm{~g} / \mathrm{L}$ after 30 days. In the study by Kosch and others, ${ }^{19}$ a total monthly FGC dose of $375 \mathrm{mg}$ led to an increase in hemoglobin of $0.9 \mathrm{~g} / \mathrm{L}$ after 6 months of treatment. Terminal kidney failure is associated with lower levels of erythropoietin and increased inflammation, which leads to reduced bone marrow production in reaction to anemia. ${ }^{25} \mathrm{~A}$ weaker response to iron supplementation could be expected in these patients.

Preservation or impairment of kidney function did not seem to affect the efficacy of FGC. Daily FGC administration also seemed to be as effective as administration at intervals of $48 \mathrm{~h}$ or longer. This analysis is important, as the optimal administration schedule is unknown for this population. During prior clinical trials, FGC was administered during dialysis, which generally occurs 2 or 3 times a week, with a period of at least $48 \mathrm{~h}$ between consecutive doses. This optimal dosage regimen remains to be confirmed in a prospective study, given that a shorter interval between doses is more convenient, especially in the hospital setting.

This study had several limitations. The study design was retrospective. The study population was heterogeneous, and many different medical specialties were involved in caring for the patients. A variety of uncontrolled confounding factors may have been present, given that retrospective chart-based studies are vulnerable to missing data. The medical chart is a legal document, so documentation of severe adverse events would be expected; however, milder adverse events may have been underestimated because of lack of documentation. There was no control group for comparison of the efficacy data. Volume contraction or expansion can alter hemoglobin levels and may have confounded the results. The margin of error for hemoglobin measurements may have confounded the results. To reduce the effect of this limitation, mean values were used for the various observation periods, and data were analyzed from a large sample of 76 patients. Iron storage was not evaluated, as ferritin values were unavailable in the follow-up period. Some patients were followed as outpatients, and we cannot exclude the possibility of blood transfusion or iron or erythropoietin administration during outpatient follow-up.

Parenteral iron therapy may be considered when oral administration of iron is contraindicated. Clinicians may choose iron dextran, iron sucrose, or FGC. All of these iron formulations have demonstrated efficacy for patients with severe chronic and end-stage kidney failure, with or without hemodialysis. ${ }^{26,27}$ However, their efficacy and safety in the elderly population remains poorly studied, and there have been no prospective, placebo-controlled trials in this age group. Nearly 30 years ago, a prospective trial of IV iron dextran was carried out in elderly patients, but it was terminated because of adverse effects. ${ }^{28} \mathrm{~A}$ retrospective study published in 2014 evaluated the safety of iron dextran in geriatric patients, $67 \%$ of whom had severe to end-stage renal failure. ${ }^{29}$ Iron dextran was considered safe and effective in this population. Cuenca Espiérrez and others ${ }^{30}$ found that a single $250-\mathrm{mg}$ dose of iron sucrose reduced the need for transfusion in elderly patients with hip fracture. Anaphylactic reaction remains a concern with IV administration of iron. In a comparative study, iron sucrose had the lowest incidence of anaphylactic reaction, followed by FGC, and then iron dextran. ${ }^{24}$

\section{CONCLUSION}

The choice of iron salt for IV infusion in elderly patients with iron-deficiency anemia remains challenging. No studies have demonstrated the efficacy of any particular iron salt for this indication. Iron sucrose may be a safe option, but its safety has 
not been demonstrated within the elderly population. In addition, there have been frequent interruptions in the supply of iron sucrose in Canada in recent years. Iron dextran might be another option, but a higher incidence of anaphylaxis limits its use. FGC is a safe choice for treating iron-deficiency anemia in elderly patients, and its supply may be more reliable. This study provides the foundation for a prospective randomized clinical trial to evaluate the efficacy and safety of FGC in the elderly population.

\section{References}

1. Haemoglobin concentrations for the diagnosis of anaemia and assessment of severity. Vitamin and Mineral Nutrition Information System (WHO/NMH/ NHD/MNM/11.1). Geneva (Switzerland): World Health Organization; 2011 [cited 2018 May 22]. Available from: www.who.int/vmnis/indicators/ haemoglobin.pdf

2. Pang WW, Schrier SL. Anemia in the elderly. Curr Opin Hematol. 2012; 19(3):133-40.

3. Patel KV. Epidemiology of anemia in older adults. Semin Hematol. 2008; 45(4):210-7.

4. Zakai NA, French B, Arnold AM, Newman AB, Fried LF, Robbins J, et al. Hemoglobin decline, function, and mortality in the elderly: the cardiovascular health study. Am J Hematol. 2013;88(1):5-9.

5. Camaschella C. Iron-deficiency anemia. NEnglJ Med. 2015;372(19):1832-43.

6. DeLoughery TG. Microcytic anemia. N Engl J Med. 2014;371(14):1324-31.

7. Muñoz M, García-Erce JA, Remacha ÁF. Disorders of iron metabolism. Part II: iron deficiency and iron overload. J Clin Pathol. 2011;64(4):287-96.

8. Clark SF. Iron deficiency anemia: diagnosis and management. Curr Opin Gastroenterol. 2009;25(2):122-8.

9. Liu K, Kaffes AJ. Iron deficiency anaemia: a review of diagnosis, investigation and management. Eur J Gastroenterol Hepatol. 2012;24(2):109-16.

10. Polin V, Coriat R, Perkins G, Dhooge M, Abitbol V, Leblanc S, et al. Iron deficiency: from diagnosis to treatment. Dig Liver Dis. 2013;45(10):803-9.

11. Rimon E, Kagansky N, Kagansky M, Mechnick L, Mashiah T, Namir M, et al. Are we giving too much iron? Low-dose iron therapy is effective in octogenarians. Am J Med. 2005;118(10):1142-7.

12. Koch S, Gloth FM, Nay R. Medication management in older adults : a concise guide for clinicians. Totowa (NJ): Humana; 2009.

13. Sheen E, Triadafilopoulos G. Adverse effects of long-term proton pump inhibitor therapy. Dig Dis Sci. 2011;56(4):931-50.

14. Auerbach M, Goodnough LT, Shander A. Iron: the new advances in therapy. Best Pract Res Clin Anaesthesiol. 2013;27(1):131-40.

15. De Falco L, Sanchez M, Silvestri L, Kannengiesser C, Muckenthaler MU, Iolascon A, et al. Iron refractory iron deficiency anemia. Haematologica. 2013;98(6):845-53.

16. Nissenson AR, Lindsay RM, Swan S, Seligman P, Strobos J. Sodium ferric gluconate complex in sucrose is safe and effective in hemodialysis patients: North American Clinical Trial. Am J Kidney Dis. 1999;33(3):471-82.

17. Larson DS, Coyne DW. Update on intravenous iron choices. Curr Opin Nephrol Hypertens. 2014;23(2):186-91.

18. Naranjo CA, Busto U, Sellers EM, Sandor P, Ruiz I, Roberts EA, et al. A method for estimating the probability of adverse drug reactions. Clin Pharmacol Ther. 1981;30(2):239-45.

19. Kosch M, Bahner U, Bettger H, Matzkies F, Teschner M, Schaefer RM. A randomized, controlled parallel-group trial on efficacy and safety of iron sucrose $\left(\right.$ Venofer $\left.{ }^{\circledR}\right)$ vs iron gluconate (Ferrlecit $\left.{ }^{\circledR}\right)$ in haemodialysis patients treated with rHuEpo. Nephrol Dial Transplant. 2001;16(6):123944.

20. Coyne DW, Adkinson NF, Nissenson AR, Fishbane S, Agarwal R, Eschbach JW, et al. Sodium ferric gluconate complex in hemodialysis patients. II. Adverse reactions in iron dextran-sensitive and dextran-tolerant patients. Kidney Int. 2003;63(1):217-24.
21. Michael B, Coyne DW, Fishbane S, Folkert V, Lynn R, Nissenson AR, et al. Sodium ferric gluconate complex in hemodialysis patients: adverse reactions compared to placebo and iron dextran. Kidney Int. 2002;61(5):1830-9.

22. Folkert VW, Michael B, Agarwal R, Coyne DW, Dahl N, Myirski P, et al. Chronic use of sodium ferric gluconate complex in hemodialysis patients: safety of higher-dose ( $\geq 250 \mathrm{mg}$ ) administration. Am J Kidney Dis. 2003; 41(3):651-7.

23. Navarro JF, Teruel JL, Liaño F, Marcén R, Ortuño J. Effectiveness of intravenous administration of Fe-gluconate- $\mathrm{Na}$ complex to maintain adequate body iron stores in hemodialysis patients. Am J Nephrol. 1996;16(4):268-72.

24. Wang C, Graham DJ, Kane RC, Xie D, Wernecke M, Levenson M, et al. Comparative risk of anaphylactic reactions associated with intravenous iron products. JAMA. 2015;314(19):2062-8.

25. Guralnik JM, Eisenstaedt RS, Ferrucci L, Klein HG, Woodman RC. Prevalence of anemia in persons 65 years and older in the United States: evidence for a high rate of unexplained anemia. Blood. 2004;104(8):2263-8.

26. Dahdah K, Patrie JT, Bolton WK. Intravenous iron dextran treatment in predialysis patients with chronic renal failure. Am J Kidney Dis. 2000; 36(4):775-82.

27. Charytan C, Levin N, Al-Saloum M, Hafeez T, Gagnon S, Van Wyck DB. Efficacy and safety of iron sucrose for iron deficiency in patients with dialysis-associated anemia: North American clinical trial. Am J Kidney Dis. 2001;37(2):300-7.

28. Bsoul H, Ciechanover M, Kohn D. [Intravenous iron-dextran in the elderly]. Harefuah. 1990;118(5):254-7. Article in Hebrew.

29. Dossabhoy NR, Turley S, Gascoyne R, Tapolyai M, Sulaiman K. Safety of total dose iron dextran infusion in geriatric patients with chronic kidney disease and iron deficiency anemia. Ren Fail. 2014;36(7):1033-7.

30. Cuenca Espiérrez J, García Erce JA, Martínez Martin ÁA, Solano VM, Modrego Aranda FJ. Seguridad y eficacia del hierro intravenoso en la anemia aguda por fractura trocantérea de cadera en el anciano [Safety and usefulness of parenteral iron in the management of anemia due to hip fracture in the elderly]. Med Clin (Barc). 2004;123(8):281-5. In Spanish, with English abstract.

Patrick Viet-Quoc Nguyen, MSc, is a Pharmacist with the Centre hospitalier de I'Université de Montréal (CHUM) and the CHUM Research Center, Montréal, Quebec.

Judith Latour, MD, is a Geriatrician with the Centre hospitalier de I'Université de Montréal, Montréal, Quebec.

\section{Competing interests: None declared.}

\section{Address correspondence to:}

Patrick Viet-Quoc Nguyen

Centre hospitalier de l'Université de Montréal

CHUM Research Center

900, rue Saint-Denis, Pavillon $R$

Montréal QC H2X OA9

e-mail: patrick.nguyen@umontreal.ca

Funding: This work was supported by the Pharmacy Department and the Geriatrics Department of the Centre hospitalier de I'Université de Montréal.

Acknowledgements: The authors would like to thank Manon Chovet and Bao-Chau Pham for their contribution to data collection. 